\title{
Proteção e promoção da infância: tensões entre coletivismo e individualismo no Brasil
}

\author{
Gilberto Lima dos Santos \\ Antonio Marcos Chaves \\ Universidade Federal da Bahia
}

\begin{abstract}
RESUMO
O objetivo deste estudo é desenvolver uma reflexão, orientada pelas concepções de individualismo e coletivismo, para compreender como se apresentam historicamente a lógica da proteção e a lógica da promoção da infância nos processos educacionais e na legislação referente à infância, no Brasil. Partese da consideração de que os conceitos de individualismo e de coletivismo têm se mostrado muito úteis para explicar fenômenos relacionados às diferenças culturais; e que as características individualistas ou coletivistas de uma cultura marcam a dinâmica das interações sociais, os valores e as atitudes. Para tanto, desenvolve-se uma apreciação de aspectos históricos da educação brasileira, que ligam suas origens à atualidade. Ao longo da discussão, são priorizados a escola e o Estatuto da Criança e do Adolescente como fenômenos atualizadores das referidas lógicas. O estudo sugere a prevalência da lógica da proteção e sua estreita conexão com os princípios coletivistas. Ao mesmo tempo, aponta para uma marcante presença do ideário religioso, católico, na educação e na legislação pertinente à infância.
\end{abstract}

Palavras-chaves: individualismo/coletivismo; proteção/promoção; infância.

\section{ABSTRACT \\ Childhood protection and promotion: tensions between collectivism and individualism in Brazil}

The aim of this study is to develop a reflection, guided by individualism and collectivism notions, about how childhood protection logic and childhood promotion logic appear historically in educational processes and in Brazilian legislation. Two important ideas are taken in consideration. First, the individualism and collectivism concepts have been successful ones to explain the phenomena related to the cultural differences. Second, individualistic or collectivistic cultural features mark the social interactions dynamics, the values and the attitudes. Then, this study appreciates some historic features of Brazilian education that link its origin to the present days. Along the discussion, priority is given to school and to Child and Adolescent Statute as phenomena that bring the above named logics up-to-date. This study suggests the protection logic prevalence and its close connection to collectivistic principles. At the same time, it indicates a powerful influence of the Catholic model on the Brazilian education and legislation related to the childhood..

Keywords: individualism/collectivism; protection/promotion; childhood.

O objetivo deste estudo é desenvolver uma reflexão, orientada pelas concepções de individualismo e coletivismo, para compreender como se articulam historicamente a lógica da proteção e a lógica da promoção da infância no Brasil. Para tanto, lançaremos um olhar aos processos educacionais e à legislação especialmente voltada para a infância.

Discutir estas e outras questões relacionadas à infância reveste-se de peculiar importância neste momento do século XXI. Primeiro, porque são cada vez mais atuantes e abrangentes os movimentos reivindicadores e/ou promotores de ações e políticas inclusivas. Isto tem possibilitado não apenas o aprofundamento de discussões sobre relações étnicas e relações de gênero, por exemplo, mas também a percepção de que a infância tem sido historicamente discriminada, enquanto categoria social, e alijada de uma participação social mais efetiva (Kramer, 2003). 
Não queremos com isso significar que todas as crianças estejam hoje, de forma óbvia ou sutil, impedidas de uma participação social mais ativa. Mesmo porque é notório que a família se configura na atualidade de modos variados, imprimindo às suas relações interpessoais dinâmicas diferenciadas. Grosso modo, pode-se perceber que as famílias mais modernas (ao contrário das mais tradicionais) tendem a escutar e respeitar as opiniões de suas crianças, levando-as em consideração ao tomar suas decisões (Casas, 1998).

Além disso, são bastante visíveis os modos pelos quais as novas tecnologias permitem às crianças (que pela sua posição social a elas têm acesso) inverter o vetor da socialização. Ao apropriar-se eficiente e rapidamente dessas tecnologias, as crianças tornam-se agentes socializadores de adultos. Iniciam os adultos no uso de instrumentos para os quais estes são amiúde resistentes (Casas, 1998).

Tratamos aqui, então, de uma questão de predominância de uma lógica articuladora de ações, políticas e processos voltados para a proteção da infância, em detrimento de sua promoção.

É importante também discutir questões sobre a infância no Brasil, tomando como orientação os conceitos de individualismo e coletivismo. Assim, abre-se a possibilidade de avançar na compreensão teórica sobre esse período do desenvolvimento humano, levando-se em consideração as peculiaridades culturais.

\section{INDIVIDUALISMO E COLETIVISMO}

Nas últimas três décadas, o conceito de individualismo/coletivismo tem sido usado com frequiência, tanto em relatos de pesquisa quanto em estudos teóricos, publicados em jornais internacionais. É um conceito que tem se mostrado muito útil para explicar fenômenos relacionados às diferenças culturais. Sua difusão foi iniciada com os estudos de Hofstede, publicados em 1980, segundo Kagitçibasi (1998).

Conforme Lonner e Adamopoulos (1996), entretanto, esses construtos teóricos foram introduzidos nas ciências sociais, nos anos 60 do século passado, por Tönnies, ao fazer a distinção entre comunidade agrícola tradicional e ambiente urbano industrial. A partir da década de 80, então, muitas discussões e pesquisas passaram a ser realizadas por vários estudiosos, a exemplo de Hofstede e Triandis. Esses estudos permitiram que os conceitos de individualismo e coletivismo se firmassem cada vez mais como indicadores de características distintivas entre culturas.
Estes conceitos não estão restritos ao campo da psicologia. Sua presença na literatura remonta aos antigos gregos, a exemplo da coletivista República (de Platão) e dos ensinamentos individualistas dos sofistas. Passa pelo cogito cartesiano, pelo empirismo britânico, pelo darwinismo social, pela fenomenologia, pela filosofia existencialista (expressões individualistas) e por Karl Marx (expressão coletivista). E, ao chegar à contemporaneidade, permite um reconhecimento crescente do Ocidente (especialmente as sociedades norte-americanas e européias) como predominantemente individualista e do Oriente como predominantemente coletivista (Kagitçibasi, 1998).

As características individualistas ou coletivistas de uma cultura marcam a dinâmica das interações sociais, os valores, as atitudes e as opções comportamentais. Ou seja, constituem-se como dimensões relevantes da subjetividade. Podemos distinguir estes dois construtos, através de uma relação de características mais comuns, tomando como base as informações disponibilizadas por Kagitçibasi (1998) e Fiske, Kitayama, Markus e Nisbett (1998).

Citando os trabalhos de vários pesquisadores, Kagitçibasi (1998) explicita algumas das características do coletivismo e do individualismo, conforme segue:

1. Em contextos individualistas, as pessoas se percebem mais através da descrição de traços e atributos. Enquanto em contextos coletivistas, as referências são os papéis e os fatores situacionais.

2. Em contextos individualistas, as emoções são mais centradas no "eu": raiva, frustração, orgulho etc. E nos contextos coletivistas, são mais centradas no "outro": simpatia, vergonha, sentimentos de comunhão interpessoal etc.

3. Em contextos individualistas, a realização eleva o self e, em contextos coletivistas, eleva tanto o self quanto a coletividade, principalmente a família.

4. A competição é mais presente em contextos individualistas e a cooperação em contextos coletivistas.

Então, podemos dizer que, de modo geral, o individualismo é caracterizado por valores individuais, comportamentos individualistas, autonomia, egoísmo, idiocentrismo, auto-realização, auto-estima individual, autopromoção, reconhecimento social, eqüidade, competição, muitas interações breves, integração social, desligamento emocional e baixa contextualização. 
Enquanto que o coletivismo é caracterizado por valores coletivistas, comportamentos coletivistas, interdependência, solidariedade, alocentrismo, atualização grupal, auto-estima coletiva, humildade, conformidade, igualdade, cooperação, poucas interações duradouras, integridade familiar, contágio emocional e alta contextualização.

Entretanto, contrariando o que pode parecer à primeira vista, as evidências apontam o individualismo e o coletivismo não como opostos que se excluem, mas como possibilidade de coexistência, em graus variados, no mesmo indivíduo ou grupo, dependendo da situação ou dos objetivos. Do mesmo modo, as evidências sugerem que não devemos confundir individualismo com modernização ou coletivismo com tradição/conservadorismo (Kagitçibasi, 1998).

Convergindo com essa perspectiva, Fiske e cols. (1998) usam os conceitos de independência e interdependência como princípios organizadores da cultura. E, embora os autores advirtam que independência não é o mesmo que individualismo, focalizar esses achados parece pertinente, pois fazem referência a aspectos da cultura relacionados ao individualismo ou ao coletivismo. Nesse sentido, Kagitçibasi (1998) assinala que, no nível individual, o self interdependente é a expressão do padrão relacional self-outro (tipicamente coletivista) e o self independente é a expressão do padrão individualista.

De acordo com esses estudos, no modelo cultural independente (predominante na América do Norte e Europa), a pessoa é caracterizada pelos seus atributos (preferências, motivos, objetivos, atitudes, crenças e habilidades), orientação para o sucesso e a autorealização, e a possibilidade de escolher. Por outro lado, em se tratando do modelo cultural interdependente (prevalente na Ásia oriental), a pessoa é caracterizada pela empatia, reciprocidade, pertença (à família, aos grupos), parentesco, hierarquia, lealdade, respeito, polidez e obrigações sociais, ou seja, pela conexão com os outros (Fiske e cols., 1998).

Neste ponto, parece útil incluir a distinção feita por Kagitçibasi (1998), ao indicar duas possíveis interpretações para o individualismo/coletivismo. Uma alternativa é baseada na orientação normativa, que salienta a ideologia e como as pessoas concebem as relações indivíduo-grupo. A outra consiste em considerar as relações self-outro. Entretanto, em sintonia com o objetivo visado neste estudo, o interesse recai sobre a orientação normativa, pois o coletivismo normativo é fundamentado na idéia de que os interesses individuais devem ser subordinados aos interesses grupais. Isso significa que, em troca de lealdade incondicional, a família, a comunidade ou a sociedade devem proteger e apoiar o indivíduo. Os aspectos normativos do coletivismo são expressões da tradição e da ideologia conservadora. Por sua vez, o individualismo normativo supõe, ao invés da supremacia do grupo, a liberdade e os direitos individuais.

Uma outra distinção interessante, entre coletivismo/individualismo horizontal e vertical, foi proposta por Triandis (citado por Gouveia, Guerra, Martinez \& Paterna, 2004). No individualismo horizontal são valorizadas a singularidade e a privacidade das pessoas. Suas vidas e seus relacionamentos são pautados pela justiça social e pela liberdade, num contexto igualitário. No individualismo vertical são supervalorizados a auto-realização e o sucesso pessoal, o poder e a liberdade, o que sugere, portanto, um contexto marcado pela desigualdade. No coletivismo horizontal são valorizadas a cooperação, a amizade, a pertença e o apoio social, maximizando a igualdade e minimizando a liberdade. No coletivismo vertical predominam a obediência, a conformidade e a hierarquia, restringindo-se a liberdade e a igualdade.

Ainda de acordo com Kagitçibasi (1998), todas as sociedades apresentam tensões entre individualismo e coletivismo, embora a ênfase possa variar na direção de um ou de outro construto. Também Schwartz, Triandis, Sinhá e Tripathi (citados por Gouveia e cols., 2004) consideram que pessoas e culturas podem ser coletivistas e individualistas simultaneamente.

Quanto ao Brasil, há indicações de uma orientação mais coletivista. Essas indicações vêm de Triandis, Hofstede, Gouveia, Albuquerque, Clemente e Espinosa (citados por Gouveia e cols., 2004). Convém assinalar, entretanto, que, embora reconheçam que há consenso quanto à predominância da orientação coletivista no Brasil, Gouveia e cols. (2004) preferem sugerir, em conformidade com os resultados de suas próprias pesquisas, que no Brasil ocorre uma combinação de individualismo e coletivismo horizontais. Os brasileiros valorizam a vida privada e a singularidade individual e, ao mesmo tempo, a conexão com os outros (convivência, afetividade, honestidade etc.). E conferem pouco valor ao egoísmo, ao poder ou ao querer colocar-se acima dos outros.

\section{A CONCEPÇÃO DE INFÂNCIA}

A infância nem sempre foi concebida como hoje o é. Trata-se de um conceito que se transformou ao longo da história. De acordo com Ariès (1981), até o 
século XI a infância não existia enquanto tal. Até o século XII, as crianças eram representadas na pintura como adultos em miniatura. Nos séculos XV e XVI, eram vistas como engraçadinhas; e eram paparicadas até por volta dos sete anos de idade. Entre os séculos XVII e XIX, em função do alto índice de mortalidade infantil, não se atribuía às crianças algo similar à personalidade do ser humano, nem com elas se desenvolvia muito apego.

Nos séculos XVI e XVII, a educação mais sistemática da criança começava em torno dos sete anos. Foi também a partir do século XVII que se desenvolveu o sentimento de que a criança deveria ser separada dos adultos em certas situações. Começava-se a perceber a infância como inocência e fragilidade, origem do sentimento moderno (Ariès, 1981).

No século XVIII, passou a existir uma preocupação com a higiene e a saúde física da criança. Nesse período, quem ia para a escola prolongava a infância. Só os meninos iam; ainda assim poucos. As meninas eram excluídas. Eram treinadas para assumir a casa e casavam cedo. Ao final do século XVIII, a escolaridade passou a durar quatro ou cinco anos (Ariès, 1981).

Os dados apresentados por Ariès (1981) referem-se à Idade Média e à Idade Moderna. A delimitação da infância evoluiu, incorporando a idéia de inocência, de fragilidade, de certa incapacidade, e evocando a necessidade de proteção e provisão. No plano internacional (no Ocidente), um marco histórico sinalizou a existência de um processo de mudança desse vetor: a Convenção das Nações Unidas sobre os Direitos das Crianças, realizada em Nova York, em 1989. Essa Convenção acrescentou um item inovador: a necessidade de promover a infância.

A perspectiva da promoção da infância toma como ponto de partida a constituição da criança como sujeito de direito. E avança no sentido de possibilitar à criança uma participação social mais ativa e consciente de seus direitos e responsabilidades, visando a permanente e efetiva atualização de suas capacidades (Casas, 1998).

\section{EDUCAÇÃO: O PREDOMÍNIO DA TRADIÇÃO COLETIVISTA}

Na penúltima década do século passado, Mizukami (1986) empreendeu um estudo com professores do ensino básico, em escolas públicas, na cidade de São Carlos (no Estado de São Paulo), buscando avaliar o que fundamenta a ação docente.
Embora sem o propósito de propor amplas generalizações, essa autora chegou a resultados curiosos. Um dos objetivos do seu estudo consistiu em confrontar as opções teóricas declaradas pelos professores com suas práticas manifestas. Os dados obtidos permitiram-lhe concluir que os professores preferem algumas abordagens teóricas estudadas nos cursos de licenciatura. Mais do que isso, evidenciou-se a seguinte ordem de preferência: abordagens cognitivista, sócio-cultural, humanista, tradicional e comportamentalista.

Entretanto, ao analisar as atividades dos professores em sala de aula, as atividades dos alunos, as formas de tratamento do conteúdo e das avaliações, a autora observou o predomínio da abordagem tradicional. Ou seja, a penúltima opção teórica transformou-se em primeira opção prática, indicando assim um descompasso ou incongruência entre os níveis de apreensão teórica e de manifestação ou realização.

Ao tecer considerações sobre esse fenômeno, a autora expressa a compreensão de que as abordagens teóricas aprendidas durante os cursos de licenciatura permaneceram "externas" aos professores, desvinculadas de sua prática pedagógica. E argumenta que essa não incorporação das teorias está relacionada às formas pelas quais os cursos de formação de professores operam. Ou seja, esses cursos operam desvinculados das situações concretas de ensino-aprendizagem.

Do nosso ponto de vista, julgamos pertinentes as conclusões dessa pesquisa, mas prontamente acrescentamos a sugestão de que é preciso observar os princípios que fundamentam o funcionamento da escola, enquanto unidade concretizadora da instituição educacional. Na verdade, consideramos que é imprescindível, mas, ao mesmo tempo, insuficiente olhar apenas o funcionamento dos cursos de licenciatura. Se o funcionamento da escola, em que atuam os professores, está baseado prioritariamente em princípios coletivistas, provavelmente essa escola oferecerá resistências ou será mesmo refratária a abordagens teóricas promotoras do individualismo.

$\mathrm{O}$ ensino que toma como referência a abordagem teórica cognitivista enfatiza necessariamente os processos cognitivos, a capacidade do aluno de processar e integrar informações. É um ensino que visa promover o desenvolvimento intelectual na direção da autonomia, pois considera que o aluno constrói seu próprio conhecimento. Sendo assim, o ponto de partida do processo de ensino-aprendizagem é a motivação intrínseca do aluno, que deve trabalhar o mais independentemente possível, de acordo com as caracterís- 
ticas do seu estágio de desenvolvimento (Mizukami, 1986). Nesse caso, portanto, é notória a forte orientação individualista.

Em se tratando da abordagem tradicional, características opostas são ressaltadas. $\mathrm{O}$ ensino baseado nessa abordagem prioriza o que é externo ao aluno: o programa, as disciplinas e, principalmente, o professor. A motivação é extrínseca ao aluno, depende das habilidades do professor para suscitar ou manter o interesse do aluno. A relação entre o professor e o aluno é verticalizada, pautada que está na autoridade do primeiro, na hierarquização. $\mathrm{O}$ aluno é um receptor de informações passivo, desempenha um papel secundário no processo de elaboração e aquisição de conhecimento. As diferenças individuais não são levadas em consideração, pois as formas de ensinar são as mesmas, independentemente da clientela (Mizukami, 1986). Nesse caso, por conseguinte, evidencia-se a orientação coletivista.

A educação é uma instituição que se manifesta em cada estabelecimento escolar. Manifesta-se através de leis, normas ou pautas estabelecedoras de regularidades de comportamentos; porque são os comportamentos dos seres humanos, afinal, ao protagonizar as práticas sociais, que objetivam as instituições. Estas, por sua vez, são composições lógicas. No caso da educação, essas composições lógicas indicam como se deve socializar, promover a inserção de um novo membro da comunidade (Baremblitt, 1996).

Segundo Baremblitt (1996), as instituições são geradas e tendem a ser transformadas, ao longo do seu percurso histórico, por forças instituintes. E o seu efeito, o seu resultado, ou seja, as leis, as normas, os padrões ou pautas (o instituído) tendem a resistir às mudanças, tendem ao conservadorismo e ao reacionarismo.

Sendo assim, podemos compreender que as primeiras forças instituintes da educação brasileira foram as ações jesuíticas. Fundada em 1534, a Companhia de Jesus, que Ponce (1994) chama de exército, passou a atuar "depois de disciplinar os seus soldados até a negação absoluta da personalidade (...)" (p. 118), e antes do final do século já dominava o ensino na Europa.

Os jesuítas chegaram ao Brasil com o primeiro Governador Geral, em 1549. Começaram catequizando os índios e educando os filhos dos colonos. Mas logo ampliaram sua atuação, criando escolas médias e superiores, similares às suas escolas européias (Ponce, 1994). Nessas escolas funcionava um plano para, dentre outros objetivos, "quebrar nos alunos o mais tímido assomo de independência pessoal" (p. 122). Vemos assim que dois dos objetivos visados pela Companhia de Jesus são: a negação da individualidade e a negação da autonomia.

Mesmo após a expulsão dos jesuítas do Brasil, a Igreja Católica manteve o monopólio da educação no Brasil. Na década de 1930, as reformas pretendidas pelo movimento renovador, baseadas no princípio do direito de todos à educação, fez com que a Igreja Católica percebesse estar seu monopólio sob ameaça e entrasse no embate ideológico de forma intensa. Ao assumir essa oposição, "a Igreja Católica tomou o partido da velha ordem e, com isso, da educação tradicional", conforme afirma Romanelli (1991, p. 144).

Nesse ponto, parece coerente a compreensão de que a educação brasileira carrega ainda as marcas dessas primeiras forças instituintes, com seu ideário coletivista. Bem como parece razoável concluir que esse ideário mantém-se atualizado, através do ensino orientado pela abordagem tradicional e através da legislação sobre a infância, conforme discutiremos adiante.

Nesse sentido, a afirmação de Kagitçibasi (1998) é esclarecedora, quando afirma que o Cristianismo, dentre outras várias religiões, também enfatizou a lealdade coletiva, ainda que mais tarde a reforma protestante tenha inserido na pauta a responsabilidade individual. Convém lembrar ainda que, para Triandis (citado por Kagitçibasi, 1998), os atributos definidores do coletivismo são: a integridade familiar e a solidariedade.

\section{A ANC E O ECA: A LÓGICA DA PROTEÇÃO}

Pensando sobre os direitos da infância e os processos educacionais, percebemos que o Estatuto da Criança e do Adolescente (ECA), editado em 1990, representa o corolário atual de um longo processo histórico de transformação do próprio conceito de infância. Funciona como uma expressão legal e legalizante dessa concepção. Ao mesmo tempo, percebemos que, para compreender melhor o processo de elaboração desse Estatuto, devemos prestar atenção a um evento antecedente da maior importância: o processo da Assembléia Nacional Constituinte (ANC), transcorrido entre 1987 e 1988. Daí resultou o texto da Constituição Federal de 1988, com um capítulo dedicado especificamente à criança e ao adolescente, fato inédito em uma Carta Magna, de acordo com Pinheiro (2004). 
O ECA regulamentou justamente a concepção sobre direitos da criança e do adolescente contida nesse capítulo. Foi, portanto, ao longo do processo da ANC que ocorreram os embates ideológicos que deram forma à concepção fixada no ECA.

Apesar dos percalços em torno de sua aplicação, devidos principalmente a insuficientes aportes financeiros dos poderes públicos, o ECA tem sido apontado por estudiosos como um marco histórico, no caso brasileiro, em termos de abordagem legal da infância. Sobretudo porque define a criança e o adolescente como sujeitos de direitos, realizando desse modo um salto qualitativo considerável em relação à legislação anterior, que os concebia como objetos (Bazílio, 2003).

Pinheiro (2004) realizou um estudo, visando compreender esse embate, em termos de representações sociais da criança e do adolescente manifestadas pelos participantes da ANC (parlamentares e não parlamentares). Das representações sociais que identificou, quatro ela considerou como sendo as mais recorrentes na história social brasileira: objeto de proteção social; objeto de controle e de disciplinamento; objeto de repressão social; e sujeitos de direitos. Através de documentos, ela analisou discurso e votações, atas e emendas populares, tomando como referência as quatro representações sociais mais recorrentes.

Numa visão geral dos dados analisados, Pinheiro (2004) concluiu que houve predominância do ponto de vista da proteção social. Apenas nas emendas populares houve predominância dos sujeitos de direitos. Em alguns momentos, a autora encontrou essas duas representações sociais associadas. Ela atribuiu essa recorrência às forças religiosas cristãs e à perspectiva dos deveres humanitários, principalmente. Por fim, constatou que no texto da $\mathrm{CF} / 88$ prevaleceu a noção de criança e de adolescente como sujeitos de direitos (e não a proteção social), que tem sido considerada, evidentemente, uma representação inovadora.

\section{PARA ALÉM DA LÓGICA DA PROTEÇÃO SOCIAL}

Preferimos argumentar, entretanto, que a concepção de criança e de adolescente como sujeitos de direitos, apesar de ser inovadora e necessária, é insuficiente, por si só, para superar a lógica da proteção social. A superação dessa lógica protetora e controladora demanda um avanço significativo na direção da promoção social da infância. Com isso, a proteção social não seria eliminada, mas incorporada a uma perspectiva mais abrangente. Pinheiro (2004) teve um vislumbre dessa possibilidade ao observar a ocorrência da associação das concepções protetoras e de sujeitos de direitos em reuniões da Subcomissão da ANC.

A perspectiva da promoção da infância foi delineada pela Convenção das Nações Unidas sobre os Direitos das Crianças. Segundo Casas (1998), esse delineamento conduziria a uma nova infância, consciente de seus direitos e das responsabilidades deles indissociáveis.

A Convenção das Nações Unidas sobre os Direitos das Crianças (www.unicef.org/brazil/dir_cri.htm) é incisiva, em seus artigos 12 a 16, principalmente, ao propor direitos sociais, liberdades, direitos à intimidade e à não ingerência em sua vida privada, a ser escutado em procedimentos judiciais e administrativos, direitos à liberdade de expressão, de associação, de pensamento, de consciência e de religião, de realização de reuniões pacíficas, direito à busca de informação etc. Sobretudo, a Convenção propõe "compromissos de desenvolver políticas pró-ativas para a promoção da infância" (Casas, 1998, p. 67).

Comparado com a Convenção, o ECA (www.presidencia.gov.br/CCIVIL/LEIS/L8069.htm) não se mostra assim resoluto ao tratar dessas questões. Ao contrário, parece bastante constrito ao não indicar compromissos em termos de políticas para a promoção da infância. Limita-se a listar possibilidades decorrentes da constituição de crianças e adolescentes como sujeitos de direitos.

Embora signifique avanços inegáveis em relação à legislação anterior, o ECA permaneceu colado à tradição protetora e controladora. Mas é compreensível que tenha sido assim, considerando-se as forças ideológicas em jogo durante a ANC, conforme mostra Pinheiro (2004); principalmente interesses religiosos cristãos de inspiração coletivista. Promover a infância, no sentido apontado pela Convenção das Nações Unidas, implica avançar para além da tradição protetora e controladora, buscando a lógica da construção individualista da liberdade e da autonomia, da consciência dos direitos e de suas inerentes responsabilidades.

\section{CONSIDERAÇÕES FINAIS}

Neste estudo, tomamos como referência os conceitos de individualismo e coletivismo para compreender como a lógica da proteção e a lógica da promoção se apresentam nos processos educacionais e na legislação pertinente à infância no Brasil. 
Numa perspectiva histórica, pudemos vislumbrar o quanto o ideário religioso (principalmente católico) é marcante na educação e no ECA; como pauta de regularidades instituídas (no caso da educação) e como forças instituintes (no caso do ECA).

As informações encontradas na literatura sugerem que o surgimento da educação no Brasil ocorreu em um cenário marcadamente coletivista, tendo como principais protagonistas os jesuítas. A ação pioneira dos jesuítas imprimiu um modelo de funcionamento às escolas, cujas pautas de regularidades, cristalizadas, conservaram-se ao longo dos anos, chegando aos dias atuais no bojo da abordagem tradicional de ensino. Não mais uma tradição orientada por princípios coletivistas tão verticalizados quanto os da época jesuítica, mas ainda assim coletivistas e resistentes às investidas inovadoras.

O processo de elaboração do ECA, por sua vez, permite-nos perceber que as forças religiosas não são apenas intensos ecos do passado, mas poderosa atuação contemporânea. Essas forças são capazes de operar tanto no sentido da conservação (no caso da educação) quanto no sentido da mudança (no caso do ECA). O sentido da mudança, entretanto, é necessariamente circunscrito pela própria orientação coletivista das forças religiosas. De modo que parece haver mesmo uma solução de compromisso, uma combinação do coletivismo e do individualismo horizontais (ao menos no ECA), expressando a tensão existente, como sugerem Gouveia e cols. (2004). São postos em pauta, simultaneamente, a singularidade e a pertença, a justiça e o apoio sociais, o acolhimento da liberdade (em contexto igualitário), mas não a sua promoção (na direção dada pela Convenção das Nações Unidas).

Pode-se depreender, a partir da leitura de Ariès (1981), que a lógica da proteção à infância surgiu por volta do século XVII, na Europa, com o desenvolvimento do sentimento de que a criança deveria ser separada dos adultos em determinadas situações, e permaneceu, ao longo dos séculos subseqüentes, compondo a concepção de infância. Essa lógica começa agora a experimentar um processo de ultrapassagem, sinalizado pela Convenção das Nações Unidas sobre os Direitos das Crianças (no plano internacional), pela lógica da promoção da infância. No Brasil, a lógica da promoção da infância emerge, ainda incipiente, através da noção de "sujeito de direito" (reconhecidamente inovadora) presente no ECA.

Para finalizar esta reflexão, deixamos algumas interrogações e reticências, para significar a possibilida- de de novas reflexões ou futuros empreendimentos investigativos, lembrando, a partir de Kagitçibasi (1998), que todas as sociedades apresentam, simultaneamente, características individualistas e coletivistas em diferentes configurações. Lembremos, ainda, de acordo com o mesmo autor, que não se deve confundir individualismo com países desenvolvidos, modernos, e coletivismo com o seu oposto.

Se a ANC e o ECA sugerem que houve uma horizontalização dos princípios coletivistas, bem como um fortalecimento dos princípios individualistas, faz sentido perguntar se estes superarão aqueles no futuro, caracterizando uma tendência. Ou se os princípios individualistas estão ficando cada vez mais consistentes no ideário religioso. Além disso, fica a sugestão de pensar sobre as lógicas da proteção e da promoção da infância de modo articulado, respectivamente, com as noções de coletivismo e individualismo.

\section{REFERÊNCIAS}

Ariès, P. (1981). História social da criança e da família (2a ed.). Rio de Janeiro: LTC.

Baremblitt, G. F. (1996). Compêndio de análise institucional $e$ outras correntes: Teoria e prática ( $3^{\mathrm{a}} \mathrm{ed}$.). Rio de Janeiro: Rosa dos Tempos.

Bazílio, L. C. (2003). Avaliando a implantação do estatuto da criança e do adolescente. Em L. C. Bazílo \& S. Kramer, Infância, educação e direitos humanos (pp. 19-28). São Paulo: Cortez.

Casas, F. (1998). Infancia: Perspectivas psicosociales. Barcelona, España: Paidós.

Fiske, A. P., Kitayama, S., Markus, H. R. \& Nisbett, R. E. (1998). The cultural matrix of social psychology. Em D.T. Gilbert, S. T. Fiske \& G. Lindzey (Orgs.), The handbook of social psychology (pp. 915-981). New York: McGraw-Hill.

Gouveia, V. V., Guerra, V. M., Martinez, M. del C. \& Paterna, C. (2004). O individualismo e o coletivismo como explicadores do preconceito frente aos negros. Em M. E. O. Lima \& M. E. Pereira (Orgs.), Estereótipos, preconceitos e discriminação: Perspectivas teóricas e metodológicas. Salvador, BA: EDUFBA.

Kagitçibasi, C. (1998). Individualism and collectivism. Em J. W. Berry, M. H. Segall \& C. Kagitçibasi (Orgs), Handbook of cross-cultural psychology: Social behavior and applications (pp. 2-49). London: Allyn and Bacon.

Kramer, S. (2003). Infância, cultura contemporânea e educação contra a barbárie. Em L. C. Bazílio \& S. Kramer, Infância, educação e direitos humanos. São Paulo: Cortez.

Lonner, W. J. \& Adamopoulos, J. (1996). Culture as antecedent to behavior. Em J. B. Berry, Y. H. Poortinga \& J. Pandey (Orgs.), Handbook of cross-cultural psychology (pp. 43-83). London: Allyn and Bacon.

Mizukami, M. da G. N. (1986). Ensino: As abordagens do processo. São Paulo: E.P.U. 
Pinheiro, A. de A. A. (2004). A criança e o adolescente, representações sociais e o processo constituinte. Psicologia em Estudo, 9(3), 343-355.

Recebido: 30/03/2006

Revisado: 05/07/2006

Ponce, A. (1994). Educação e luta de classes. São Paulo: Cortez.

Aceito: 07/07/2006

Romanelli, O. de (1991). História da educação no Brasil. Petrópolis, RJ: Vozes.

\section{Sobre os autores:}

Gilberto Lima dos Santos: Mestrando, Curso de Mestrado em Psicologia, Departamento de Psicologia, Faculdade de Filosofia e Ciências Humanas, UFBA, Salvador. Endereço para correspondência: Rua Antônio Balbino, 37 - Maristas - 48.970-000 - Senhor do Bonfim/BA. Endereço eletrônico: gilblimas@ hotmail.com.

Antonio Marcos Chaves: Professor Adjunto IV - Departamento de Psicologia, Faculdade de Filosofia e Ciências Humanas, Universidade Federal da Bahia. Endereço para correspondência: Av. Otávio Mangabeira, 11.881, M4-06 - 41.650-000 - Salvador/BA. Endereço eletrônico: amchaves@ufba.br. 